\title{
Aprender e ensinar: o dueto do estágio docente
}

\author{
SIDINEI ROCHA-DE-OLIVEIRA \\ Universidade Federal do Rio Grande do Sul / Escola de AdministraçÃo, Porto Alegre - RS, Brasil \\ GABRIELA DeLUCA \\ Universidade Federal do Rio Grande do Sul / Escola de Administração, Porto Alegre - RS, Brasil
}

\begin{abstract}
Resumo
Nos últimos dez anos, a expansão do Ensino Superior brasileiro, por meio de diferentes políticas públicas, também aumentou a necessidade de um número maior de professores. No entanto, a formação de docentes não tem acompanhado essa demanda em ritmo e qualidade, já que os programas de pós-graduação priorizam a formação de pesquisadores. Um dos poucos momentos voltados à formação docente é o estágio, embora sua prática seja, muitas vezes, negligenciada pelos programas (JOAQUIM, NASCIMENTO, BOAS et al., 2011; JOAQUIM e BOAS, 2011; SANTOS e HELAL, 2013). Acreditando que o estágio docente pode constituir um espaço rico para o aprendizado do pós-graduando, este artigo tem por objetivo apresentar elementos inerentes à prática do estágio docente, refletindo sobre ela a partir de uma narrativa confessional conjunta. Essa reflexão é desenvolvida a partir de relatos e discussões de professor e aluna, registrados em seus diários de aula durante o estágio docente e apresentados aqui de modo confessional (VAN MAANEN, 1995, 2011, 2015). Da experiência empírica e das leituras teóricas, entendemos que três pontos se destacaram: o processo de formação docente e os dilemas na preparação do ensinar e do pesquisar; os aspectos técnicos do estágio docente; e a vivência do estágio docente como uma via de aprendizagem recíproca, na qual estagiário e professor descobrem o que é desempenhar essa atividade, como vivenciamos em nossa experiência. Este artigo não tem a pretensão de encerrar a discussão, mas instigar a reflexão sobre práticas de ensino e carreira docente no contexto nacional.
\end{abstract}

Palavras-chave: Estágio docente. Carreira docente. Narrativa confessional.

\section{Learning and teaching: a confessional tale}

\begin{abstract}
Over the past ten years, the expansion of higher education in Brazil, through different public policies, has increased the need for a greater number of professors. However, the efforts to prepare professors have not accompanied this increase either in rate or quality, as graduate programs tend to prioritize training for research. One of the few moments - often overlooked by post-graduate programs - focused on preparing future professors is internship, where students practice teaching in graduation courses, supervised by professors (JOAQUIM, NASCIMENTO, BOAS et al., 2011; JOAQUIM and BOAS, 2011; SANTOS and HELAL, 2013). Believing that internships provide a rich environment for post-graduation student's learning, this study aims to present elements typical of this activity. To do, we reflected on an internship based on discussions between a supervisor professor and the student, recorded in the student's class diaries during the course of the internship and presented here in form of a confessional tale (VAN MAANEN, 1995, 2011, 2015). From the internship experience and the theoretical readings, three points were highlighted: the process of preparing post-graduate students to teach in higher education and the dilemmas they face in preparation for teaching and research; technical aspects (planning, execution and evaluation) of internship; and the experience of internship as a way of mutual learning, in which student and professor discover what it is to carry out this task. Finally, this work does not intend to finish this discussion, but to instigate reflection on teaching methods and academic careers in the national context of practical teaching and research.
\end{abstract}

Keywords: Internship. Academic Career. Confessional Tale.

\section{Aprender y enseñar: el dúo de la pasantía docente}

\section{Resumen}

En los últimos diez años, la expansión de la enseñanza superior brasileña, por medio de diferentes políticas públicas, aumentó también la necesidad de un mayor número de profesores. No obstante, la formación de docentes no ha atendido a ritmo y con calidad a esa demanda, ya que los programas de postgrado priorizan la formación de investigadores. Uno de los pocos momentos dedicados a la formación docente es la pasantía, aunque muchas veces su práctica sea descuidada por los programas (JOAQUIM et al., 2011; JOAQUIM y BOAS, 2011; SANTOS y HELAL, 2013). Por considerar que la pasantía docente puede ser un espacio rico para el aprendizaje del alumno de postgrado, este texto tiene como objetivo presentar elementos peculiares de la práctica de la pasantía docente, reflexionando sobre esta desde una narrativa confesional conjunta. Esta reflexión se desarrolla a partir de los relatos y discusiones de profesor y alumna, registrados en sus diarios de clase durante la realización de la pasantía docente, y presentados aquí de modo confesional (VAN MAANEN, 1995, 2011, 2015). De la experiencia empírica y de las lecturas teóricas, deducimos que hay tres puntos que se destacan: el proceso de formación docente y los dilemas en la preparación del enseñar y del investigar; los aspectos técnicos de la pasantía docente; y la vivencia de la pasantía docente como una vía recíproca de aprendizaje, en la cual pasante y profesor descubren lo que es desempeñar esa actividad, como vivenciamos en nuestra experiencia. Finalmente, este trabajo no pretende cerrar la discusión, sino instigar la reflexión sobre las prácticas de enseñanza y la carrera docente en el contexto nacional.

Palabras clave: Pasantía docente. Carrera docente. Narrativa confesional. 
Se quer entender o que uma ciência é, você deverá olhar primeiro Não para suas teorias ou conclusões nem para o que seus apologistas dizem; Você deverá olhar para o que os seus praticantes fazem. (CLIFFORD GEERTZ apud VAN MAANEN, 2011, p. 73, tradução nossa)

Professor (P): O caminho foi sinuoso, mas hoje tenho a tranquilidade de saber que encontrei aquilo que buscava. Da indecisão à certeza: pensei estudar Farmácia, Estatística ou Artes Cênicas; ainda em dúvida, optei por Administração. O curso dos indecisos logo se mostrou uma escolha acertada; de estágio em estágio, cheguei logo a um posto de chefia numa grande empresa. Da certeza à indecisão: ter uma equipe, bom salário, perspectiva de carreira e reconhecimento não foram suficientes diante dos choques de valores vivenciados no mundo corporativo. Ainda surpreso com o tratamento quase desumano dado aos estagiários e às práticas eticamente contestáveis, abandonei a grande empresa e comecei o mestrado. Seria professor, para tentar mudar as práticas que sofri e questionei ao vivenciá-las.

Aluna (A): Como a perspectiva histórica aponta, é no presente que fazemos sentido do passado. Hoje, observo os últimos dez anos de minha vida e os desvios, dilemas e conflitos aparecem como um conjunto coerente que me trouxe até aqui: o mestrado no curso de Administração, no mesmo espaço em que me graduei. Já não sou a mesma, mas daquela nasceu a de agora. Depois de estágios e empregos, mais voltados a práticas e modelos estratégicos em Gestão de Pessoas, imaginei um time off na academia que veio a ser meu status primário de vida profissional. Primeiro, a vontade de descobrir o modelo ideal de Recursos Humanos (RH) Estratégico(s). Depois, a miscelânea teórica com a qual me deparei me desafiou a outros objetivos de pesquisa. Para além disso, a docência, relembrada dos tempos de infância, ensinando a ursos de pelúcia, agora se inscreveu em mim, como um sonho em vida.

P: Ser professor se tornou minha vida, a sala de aula seria meu espaço de renovação, o meio semanal de carregar as energias e manter o caminho. Um palco em que muitas vezes atuava sozinho, trabalhando e brincando com a audiência. Com estudo e dedicação ao ensino, eu me senti cada vez mais seguro e certo do trabalho de formação que realizava. Ingressando como professor na pós-graduação, surgiu um novo desafio: era preciso aprender a dividir esse espaço, assumir a responsabilidade de contribuir para a formação de quem será um futuro professor. Eu era responsável pelo primeiro estágio docente. Momento de dúvidas, inseguranças e incertezas. Estou preparado?

A: Ser professora tornou-se um objetivo tão real para mim que, já no primeiro semestre do mestrado, eu desejei fazer o estágio docente. Conversando com meu orientador, decidimos que eu assistiria às aulas como ouvinte neste primeiro semestre para, no segundo, fazer o estágio. Que aventura! A vivência principiante me permitiu observar, ler e aprender sobre docência, bem como criticar a negligência com o tema nas disciplinas do programa de pós. Quando chegou a hora do estágio, a pergunta primordial era: E agora? Como faz? Oxalá, um orientador que aprecie um café para discutir essas angústias!

P: No estágio docente nos confrontamos com o desafio de "ensinar a ser professor", tarefa árdua, que, mesmo nas escolas de Educação, não há muitas certezas do "como?". Estando em um programa que deixa a responsabilidade pela formação docente totalmente a cargo dos orientadores, a formação dada aos discentes varia do espectador, que apenas assiste como outros alunos, ao abandono, quando o discente assume a responsabilidade da sala de aula por completo e o professor responsável raramente aparece. Tais problemas são evidenciados de modo direto nos estudos de Sá e Moura (2008), Bezerra e Helal (2009), Joaquim e Boas (2011), Joaquim, Nascimento, Boas et al. (2011), mas refletem problemas maiores relativos à formação docente para o Ensino Superior, como evidenciam os trabalhos de Cunha (2009, 2011, 2014) e Azevedo e Cunha (2014).

A: A vivência do estágio, combinada às leituras independentes do tema, à disciplina de método de pesquisa em Gestão de Pessoas na pós e às frequentes conversas com meu orientador, via de regra no intervalo e depois das aulas, as apaziguou, substituindo angústia por revolta. Em diálogos cotidianos, a insegurança sobre o "dar aula" era quase unânime entre colegas, fazendo-nos perguntar por que raios não havia uma disciplina na pós dedicada ao tema, afinal, mesmo nos formando pesquisadores, o emprego a ser conquistado será o de professor. Novamente: Como faz? Ingênua, no início, crendo ser uma discussão inexistente, percebi que já é uma temática inflamada desde Tragtenberg (1990) e sua crítica à quantificação acadêmica. E aí? Já é hora! Já é hora... 
A partir da vivência de um estágio supervisionado no Programa de Pós-Graduação em Administração, da prática constante de diálogos entre professor e, à época, aluna, e, complementando, do exercício da reflexividade (BOURDIEU, 2001), optamos por "confessar" as práticas de estágio a partir da experiência compartilhada. Afinal, o que significa "tornar-se professor"? Aparentemente, essa pergunta e as ações que poderiam se dar a partir dela não são consideradas nos programas de formação de mestres e doutores no campo da Administração. No entanto, as pessoas em formação tendem a ocupar esse status - cargo - no futuro. Refletindo sobre isso nos perguntamos: são os estudantes ou os professores que precisam aprender sobre ensino aprendizagem? A partir de uma orientação confessional (VAN MAANEN, 2015), buscamos expor as realizações, dúvidas, medos e questionamentos no processo de aprender a ensinar, a partir da realização do estágio docente formal na disciplina "Sociologia Aplicada à Administração", do curso de graduação em Administração, compartilhado entre professor e aluna. Assim, temos por objetivo apresentar aquilo que consideramos acertos - e também erros, dúvidas e inseguranças que podem ser ultrapassadas.

Em suma, este artigo apresenta os elementos próprios da prática de estágio docente na área de Administração, refletindo sobre ela a partir de uma narrativa confessional conjunta. Esse exercício de pensar a formação docente é desenvolvido a partir de relatos e reflexões de professor e aluna registrados em seus diários de aula durante a realização do estágio docente no segundo semestre de 2013. A inspiração etnográfica na condução do método e o diálogo com autores que propõem a necessidade de discutir e mudar as práticas dos estágios docentes na área de Administração fazem deste estudo uma reflexão sobre o duplo status vivenciado por quem trabalha na pós-graduação, que se divide entre pesquisador e professor, não raramente negligenciando sua atuação no segundo.

\section{PANORAMA TEÓRICO}

Nos últimos dez anos, a expansão do Ensino Superior no Brasil, por meio de diferentes políticas públicas, tornou-se um novo fenômeno social. Como resultado da ampliação de vagas nos cursos universitários, há necessidade de um número maior de professores. No entanto, a formação de docentes não tem seguido em ritmo e qualidade necessários (CUNHA, 2014), pois um dos principais desafios nos processos seletivos tem sido o recrutamento e a seleção de professores qualificados, com formação profissional, experiência e conhecimento (BEZERRA e HELAL, 2009).

Ao que parece, apesar da formação de mestres e doutores também se expandir, a prioridade dessa formação não está voltada à docência. Essa incongruência pode ser decorrência do excessivo direcionamento à pesquisa, em detrimento da formação para a docência ou, ainda, como ressalta Cunha $(2009,2011)$ da preparação fragmentada que separa ensino e pesquisa, colocando estes quase como opções de direcionamento profissional, quando a universidade deveria ser um espaço de formação das três dimensões (ensino, pesquisa e extensão) da atuação do professor de Ensino Superior no Brasil.

Ao analisar as próprias políticas públicas, podemos notar um paradoxo, pois os planos nacionais de pós-graduação destacam a pesquisa como foco dos programas de pós-graduação e estabelecem um rígido sistema de avaliação com base na produção científica, estando cientes de que são esses mesmos programas os responsáveis pela formação de docentes para atuar nas instituições de Ensino Superior (JOAQUIM, NASCIMENTO, BOAS et al., 2011). Como resultado, mestres e doutores formados na atualidade têm melhor preparação para atuar no campo da pesquisa e não atendem às necessidades do Ensino Superior (PIMENTEL, MOTA e KIMURA, 2007). No intuito de desenvolver essa formação, os programas passaram a incluir em seus currículos a prática de docência, por meio da realização do estágio docência, como forma de levar a pessoa em formação a uma experiência que permita o desenvolvimento de competências necessárias às atividades de docente (JOAQUIM, NASCIMENTO, BOAS et al., 2011; JOAQUIM e BOAS, 2011; SANTOS e HELAL, 2013).

Uma formação voltada à docência se faz saliente pela necessidade de conhecimento, domínio das rotinas acadêmicas e das práticas de ensino, estes dois últimos somente possíveis pela vivência de docentes em formação. A falta dessas habilidades nos processos seletivos é uma evidência da dimensão do desafio na formação de futuros professores. Segundo Bezerra e Helal (2009, p. 14), a pessoa deverá ter "uma boa capacidade didático-pedagógica e, principalmente, vontade de fazer da profissão docente uma forma de 'fazer diferença' na formação acadêmica e profissional dos seus alunos". E o desafio se mantém, porque, ainda hoje, o que se preza nos currículos, seja de discentes como de quem está em avaliação na candidatura a uma vaga docente, são os saberes e competências relativos à pesquisa (PENA e LIMA, 2012). 
Além disso, a Coordenação de Aperfeiçoamento de Pessoal de Nível Superior (Capes), órgão responsável por avaliar os programas, enfatiza os critérios de avaliação desses saberes e dessas competências na produção acadêmica, o que também inibe possíveis ações relacionadas à formação docente. Assim, ao menos no Brasil, parece que se preparam pesquisadores, mas se contratam professores, fazendo com que "nessa trilha, a atividade de ensino parece atrapalhar a pesquisa, razão pela qual, não raro, é encarada como os ossos do ofício" (PENA e LIMA, 2012, p. 2). Esses autores percebem que, apesar de mestres e doutores estudarem, prioritariamente, para ser pesquisadores, quando egressos, destinam-se a instituições não universitárias, dedicadas não à pesquisa, mas à docência.

E aí?

Na verdade, Pena e Lima $(2012$, p. 1) resumem bem o que vivemos na prática, pois apontam que

[...] em tese, os programas de pós-graduação stricto sensu contribuiriam para formar professores e pesquisadores críticos capazes de refletir e compreender o processo educativo e a epistemologia do conhecimento, seus limites, métodos e possibilidades. Entretanto, eles estão prioritariamente voltados à formação do pesquisador, e visivelmente distantes da formação pedagógica.

Embora se reconheça a importância de saberes específicos para o exercício da profissão de professor do Ensino Superior, falta destaque para a valorização oficial desses saberes pedagógicos. Como resultado, a formação de docentes para o Ensino Superior se apresenta em movimentos dispersos e não institucionalizados. A carreira dos professores nas universidades está centrada em uma avaliação em que predomina a produção científica, direcionando seu trabalho e fragilizando ainda mais suas atividades de formação para a docência (CUNHA, 2009) - como é o caso do estágio.

O estágio docente é uma prática implementada pela Capes para a vivência do magistério no Ensino Superior, com a preocupação de institucionalizar, nos diferentes programas de pós-graduação, a necessidade de uma orientação para a atuar no ensino. Entretanto, acerca dessa ação, Pena e Lima $(2012$, p. 3) colocam uma questão pertinente: "tais programas dispõem de professores comprometidos com a formação pedagógica dos mestrandos e doutorandos?". Na verdade, o estágio é apenas obrigatório para bolsistas da Capes. E, na prática, o que ocorre é a pessoa que orienta "entregar" a turma para quem fará o estágio (PENA e LIMA, 2012), o que vai de encontro à sugestão, talvez em tese, de que a prática de estágio funciona basicamente pela imitação (SANTOS e HELAL, 2013).

Joaquim, Nascimento, Boas et al. (2011, p. 1148) destacam a importância do estabelecimento "de critérios claros e objetivos dos métodos avaliativos do estágio docência e mais retorno aos estagiários, e que o professor titular não se isente de suas responsabilidades, ao entregar a disciplina em sua totalidade ao professor aprendiz", assumindo a participação durante o estágio para que este tenha uma contribuição tanto para a formação do aluno como para a prática reflexiva do professor sobre o trabalho docente. Destacam, para isso, a importância do planejamento das atividades e dos objetivos das disciplinas que também poderia ser uma forma de potencializar os ganhos provenientes dessa experiência.

O estágio docente se mostra um processo de aprendizado e reflexão das pessoas envolvidas - seja professor, estagiário ou alunos da disciplina. Como apontam Joaquim, Nascimento, Boas et al. (2011, p. 1149), "a reflexão sob a ação e sobre a ação, assim como a autonomia dos pós-graduandos promovem seu desenvolvimento pessoal. Logo, a reflexividade é intensificada, o que promove o aprendizado e a geração do conhecimento".

Segundo Joaquim, Nascimento, Boas et al. (2011), a substituição do professor titular responsável pelo estagiário, sem orientação e acompanhamento, não configura estágio, mas uma forma precária de atuação docente, comprometendo tanto a formação da turma de graduação como a do futuro docente. Para que o resultado do estágio seja positivo, os autores propõem 5 pontos a observar:

1. Planejamento da disciplina.

2. Contato profissional com a atividade docente.

3. Aproximação e relacionamento com o professor titular da disciplina.

4. Dificuldades enfrentadas no estágio docente.

5. Aprendizagem e habilidade adquirida no desenvolvimento das atividades desempenhadas. 
No trabalho de Joaquim, Nascimento, Boas et al. (2011), entre as principais dificuldades relatadas pelos estudantes estão: a falta de acompanhamento por parte da pessoa responsável pela disciplina, que não ofereceu suporte durante a realização da atividade, deixando, esta sob responsabilidade exclusiva do aluno. Segundo os autores, em alguns casos, os estagiários sequer receberam a informação sobre objetivos da disciplina, resultando em prejuízos para o curso e para a turma.

Essa proximidade com o professor responsável pela disciplina é fundamental para que o estágio alcance bons resultados. Por meio da interação, a pessoa que faz o estágio pode refletir sobre o processo de ensino-aprendizagem, constituindo uma formação mais ampla da atuação docente. Dessa forma, para a interação entre professor e estagiário Joaquim, Nascimento, Boas et al. (2011) sugerem reuniões periódicas entre eles e, se possível, com os orientadores, quando não forem a mesma pessoa. Também poderiam ser realizadas as avaliações do desempenho das pessoas envolvidas para que possam ter feedback sobre seu trabalho e identificar possíveis mudanças - inclusive na forma de condução da disciplina pelos professores titulares.

Como se observa, o estágio docente pode constituir um espaço rico para o aprendizado do pós-graduando, permitindo aprimorar a prática docente e técnicas didáticas e melhorar a interação com os alunos por meio da atuação e observação das diferentes formas de aprendizado. No entanto, para que o estágio seja produtivo, é essencial a presença do professor responsável pela disciplina com os alunos, de modo que seja possível: 1) o confronto do estágio e disciplina relacionada à formação para a docência, no intuito de aliar teoria e prática; 2) a interação com alunos da graduação; 3) o aperfeiçoamento, por meio da prática, de técnicas de oratória - entenda-se domínio da língua e expressão; 4) a experiência de tomada de decisão com bases pedagógicas; e 5) lecionar uma disciplina que não pertencia à área de concentração de seu projeto de mestrado ou doutorado, como em determinados casos, nos quais foi apontado como grande e enriquecedor desafio (JOAQUIM, NASCIMENTO, BOAS et al., 2011).

Indo além, Bastos, Tourinho, Yamamoto et al. (2011) apontam que a formação de professores é complexa e merece ser central na discussão sobre a melhoria da qualidade da educação no Brasil, devendo ser central na agenda de especialistas, pesquisadores e governantes. Entre os pontos ressaltados pelos autores, mais uma vez aparece a dicotomia na formação pesquisador-docente, que se apresenta mais visível no início da trajetória profissional de jovens mestres e doutores, uma vez que no processo de preparação para a carreira futura prevalece o direcionamento à pesquisa.

\section{ESCLARECIMENTOS METODOLÓGICOS}

Tendo este panorama teórico, retomamos o estágio docente que realizamos no segundo semestre de 2013, na disciplina "Sociologia Aplicada à Administração", que faz parte do segundo semestre o curso. Durante o estágio, já falávamos em escrever a respeito da relação mestre-aprendiz que se estabeleceu entre nós. Com o tempo, percebemos que o fato de resolvermos elaborar o artigo fez com que pensássemos e discutíssemos ainda mais o "dar aula", refletindo subjetiva e objetivamente. No fim, já não sabíamos o que era causa e o que era consequência, aparentando ser um processo em ciclo de ensinar, aprender, refletir e discutir: refletíamos, pensávamos no artigo, líamos, discutíamos e, sem parecer fazer nenhum sentido, tudo passava a fazer sentido. Não havia ordem, mas era genuíno: vivemos a experiência nela mesma. Não fazíamos porque queríamos produzir, fazíamos porque "parecia certo". Nesse sentido, nos aproximávamos da relação mestre e aprendiz, na qual o conhecimento e a prática de um ofício são passados em uma relação próxima, no aprender olhando, observando, fazendo - e o mestre indicando correções (RUGIU, 1998). Um processo de aprendizagem artesanal, tal qual Mills (1959) já apontava. Como sempre, tudo imbricado.

Trabalhando em conjunto, ao longo de um semestre, compartilhamos memórias e perspectivas dessa experiência, bem como confissões sobre medos e inseguranças quanto ao processo de aprender a ensinar. Entre períodos e cafés, resolvemos, enfim, compartilhar essa experiência, próximo ao que seria uma narrativa confessional (ALCADIPANI, 2013), buscando menos desmitificar um processo de pesquisa e mais ampliar o conhecimento sobre os desafios desse aprendizado, muitas vezes renegado nas universidades brasileiras e tão dependente dele no campo de pesquisa acadêmica. Por isso, optamos por buscar 
trabalhos confessionais que expressem as reflexões no decorrer do percurso, sem a preocupação de conclusões que encerrem a discussão (VAN MAANEN, 2015).

Com isso, acreditando que a retomada de interdisciplinaridade e de novas ideias também pode contribuir para aprofundar a discussão, trazemos orientações do gênero confessional (JOVIANO, 2008), próprio da Literatura e da História, similares entre si devido à narratividade. Ao tratar da "escrita de si", Joviano (2008, p. 4), aponta que "há textos nos quais se percebe a interseção entre indivíduo e suas vivências, como as autobiografias, as memórias, as cartas e os diários". Nossa forma de escrita está suportada por Van Maanen (2015), que incentiva modos ensaísticos de escrita dentro da academia, principalmente quando esse estilo faz parte da teoria exposta. Para exemplificar, o autor apresenta Everett Hughes, que escreveu ensaios científicos de pesquisas etnográficas, as quais pressupõem um envolvimento qualitativo entre quem pesquisa e seu campo (VAN MAANEN, 1995). Aproximado da etnografia (VAN MAANEN, 2011), o estilo confessional explicita o que é vivido em campo, a partir do ponto de vista de quem o pratica no dia a dia - por isso a etnografia. Com tudo isso, preferimos narrar os passos que demos mais que apresentar técnicas e métodos prescritos.

Como mencionamos, a ideia do trabalho iniciou durante o estágio, em um processo circundado pela reflexividade (BOURDIEU, $2001)^{1}$. Já com preceitos etnográficos, mantivemos um diário de campo, o qual foi de grande utilidade quando voltamos a falar do assunto e, de fato, escrever o artigo. Ao final do semestre de 2013, com prazos estourando e trabalhos a ser entregues, acabamos deixando a ideia do artigo de lado, para o futuro próximo. Tal futuro viria um ano depois, no final de 2014. Retomamos o trabalho, tomando outro café, e resolvemos escrever em "estilo mais poético", a partir da lembrança de Alcadipani (2013). Dele, partimos para um referencial tanto metodológico, que nos levou a Van Maanen $(1995,2011,2015)$ - e nos encantou - como ao referencial teórico, que também se mostrou rico. Depois de trocas de ideias, desenhamos a estrutura do texto, mais aberta que fechada, e abrimos um documento compartilhado no Google Docs, de modo a permitir que ambos o editassem, onde fosse e quando fosse. Depois de incluir conteúdo, houve nova reunião para discutir o que foi feito, as ideias que surgiram, as novas reflexões. Voltamos a escrever. O movimento de "idas e vindas", recorrentemente descrito em trabalhos etnográficos (ou com inspiração em), também se mostrou aqui, neste dueto confessional.

Ao fim, optamos por apresentar os relatos separadamente, respeitando o fato de que cada pessoa tem um ponto de vista - também com preceitos etnográficos. O relato almejou respeitar alguns critérios, de modo que pudéssemos retomá-los e compará-los, buscando suas similaridades e diferenças, para enriquecer a discussão final, Baseamo-nos nos cinco apontamentos de Joaquim, Nascimento, Boas et al. (2011). Mesmo com eles, decidimos que a liberdade narrativa deveria vir antes desse limite estrutural.

O resultado final do texto elaborado, com exceção dos parágrafos introdutórios e dos relatos individuais, é um texto que pertence a ambos, com ideias escritas na interação: um efetivo exercício de trabalho em coautoria, um dueto de uma só voz, tal como acreditamos que deve ser a experiência do estágio docente.

\section{DA ALUNA: CONFISSÕES DE UMA AMADORA}

Durante o segundo semestre de 2013, o mesmo em que fiz o estágio docente com meu orientador, também mantive um grupo de estudos entre discentes. Nosso intuito era ter encontros semanais para discutir o que não era tratado em aula, em geral métodos de pesquisa e de docência. Nesses encontros, eu e uma colega discutíamos sobre pedagogia para adultos e compartilhamos conversas que tivemos com nossos orientadores. Nesse diálogo, percebemos nossa "sorte": enquanto alguns colegas relatavam casos traumáticos de estágio docente e orientação, nós duas tínhamos uma abertura de discussão que resultava em riqueza no aprendizado - e, depois eu viria a descobrir, uma abertura com a turma que presenciaria a vivência desse dueto. Assim, percebi como essa relação dialógica é crucial para o mestrado, para a aprendizagem, para o estágio docente, para o projeto de dissertação, enfim, para a cabeça - e, porque não, para a felicidade. Percebi que eu tive sorte.

${ }^{1} \mathrm{O}$ autor destaca a relevância de um processo reflexivo na pesquisa tanto na observação do assunto de pesquisa quanto na reflexão do próprio pesquisador. Para Bourdieu (2001, p. 694), "a reflexividade, que é sinônimo de método, mas uma reflexividade reflexa, baseada num trabalho, num olho sociológico permite perceber e controlar no campo, na própria condução da pesquisa os efeitos da estrutura social na qual ela se realiza”. 
Eu não sei o por quê, mas logo no início do mestrado eu já compartilhava pensamentos para meu orientador - acho que ele deu abertura, logo quando se apresentou a todos no primeiro dia de aula: ele vestia camiseta, jeans e tênis. Esse modo de vestir-se parecia materializar a abertura para conversa, o que vai ao encontro do apontamento de Santos e Helal (2013) sobre a melhor relação aluno-professor quando existem práticas simples de autenticidade, apreço e empatia. Autenticidade é relativa à realidade da personalidade do professor, que deve ser verdadeira, em uma relação pessoa-pessoa, e não autoridade-subordinado. $O$ apreço é a preocupação com o aluno, considerando-o uma pessoa com vontades, gostos e dificuldades. Por fim, a empatia do professor em se colocar na pele do aluno. Essas práticas facilitam o relacionamento e tendem a facilitar, também, o aprendizado.

Cruzamos no corredor durante esse período, mas não falamos muito. Apenas coisas triviais, dicas básicas de estudo, calmantes em formato de conselhos. Nesse primeiro semestre o contato aumentaria depois: a disciplina dele no programa de pós-graduação e minha participação em uma de suas turmas de graduação, como ouvinte. A disciplina da pós foi importante, mas o acompanhamento da graduação foi mais. Eu pedi a ele para assistir às aulas, sem compromisso, pois queria me familiarizar com o tema da disciplina antes de fazer o estágio formal no segundo semestre. Mal sabia eu que seria uma das minhas melhores ideias: além de me aproximar do orientador, tal experiência como ouvinte da turma de graduação me levou a realmente me comprometer com o mestrado - as aulas eram na sexta-feira à noite - e, de alguma forma, preparou-me para o segundo semestre, quando eu faria o estágio. Foi um momento em que realmente pude observar meu orientador como aluna, mas com critérios de (pretensa) professora.

O estágio formal (como o primeiro ocorreu na condição de ouvinte, não foi registrado junto ao programa de pós), na disciplina "Sociologia Aplicada à Administração", começou no segundo semestre. Iniciamos nossos encontros para discutir plano de aulas antes de termos concluído os processos burocráticos de oficialização e formalização do estágio. Esse momento, anterior ao início das aulas, mostrou-se fundamental, principalmente para que eu, como aprendiz, pudesse preparar-me com maior profundidade. Nesse sentido, preferimos não nos basear nos prazos estipulados pelo programa e demos início ao estágio no momento em que consideramos adequado. Tudo parecia confuso, na época, mas hoje faz sentido. Construímos o plano na vivência, acertando pontos cruciais no início, mas mantendo uma abertura para ajustes, de acordo com o ritmo da turma. Na verdade, todas essas coisas nunca ficaram totalmente claras para mim, mas eu estava tranquila porque ele me passava tranquilidade, não por aparentar ter todo o conhecimento, mas porque transparecia uma preocupação empática com a turma que deixava a mim - e à própria turma - segura. Trabalhar Max Weber, Karl Marx, Émile Durkheim e Pierre Bourdieu era instigante; além disso, a apresentação do primeiro dia, sob o rótulo de "professora assistente", provavelmente colaborou para eu obter maior respeito junto à turma. O primeiro dia de aula foi um espetáculo: meu orientador fez aquela linha do tempo para situar o surgimento da Sociologia e da Administração e a turma a elogiou. A linha do tempo situa em qual espaço e tempo nos encontramos e como chegamos aqui, teoricamente no campo da Administração, também facilitando o entendimento de "para onde vamos" com a disciplina. Foi esclarecedor para a turma e para mim.

Na segunda semana eu já deveria dar parte de uma aula sobre Émile Durkheim. Para isso, reunimo-nos um dia antes, para eu mostrar a apresentação que havia planejado. Iniciava com uma breve dinâmica, seguida da apresentação do conteúdo. Tirei algumas dúvidas, além de expressar meu medo quanto a ser questionada sobre algo que eu não saberia. Combinamos dar a aula em parceria e, qualquer coisa, ele responderia por mim - possibilidade sempre presente, já que estávamos em todas as aulas juntos. $O$ decorrer dessa aula foi ótimo, contando com a participação da turma, a qual se mostrou entusiasmada. Depois de um ano, ainda recordo desta turma e penso que o estágio docente é um processo dialógico entre professor-estagiário e entre estes e a turma.

Essa abertura para o novo refletiu nas aproximações subsequentes. Em uma das aulas, em que questionamos "o que é real", um aluno, que se apresentou como criacionista, ficou todo o intervalo conversando conosco. Em outro dia, outro aluno também nos procurou no intervalo, agora pedindo conselhos sobre fazer ou não tatuagens - eu havia exposto um pouco da minha temática de dissertação. No final de outra aula, um grupo de alunos aguardou pacientemente que outras pessoas tivessem suas dúvidas individuais sanadas por nós, até sentirem a sala livre para que expusessem suas inquietações. Durante esse semestre, foi praxe ficarmos em sala após a aula, tirando dúvidas individuais e coletivas. Contudo, nesta, foi especial. O grupo queria conversar sobre o Centro Acadêmico da Escola de Administração (CAEA). Queriam dicas, porque iriam se candidatar como oposição. Por eu ser representante discente, na época, me aproximei do grupo antes e depois das eleições - eles foram eleitos - pensando em estreitar os relacionamentos entre graduação e pós.

Na semana antes da primeira prova, o professor e eu falamos a respeito dela, comentando como a turma era sensacional e como era desafiador aplicar uma avaliação anacrônica ao grupo. Além disso, também nos questionamos sobre o que a turma 
pensava da aula e resolvemos, ao invés de aplicar somente o questionário padrão de avaliação do estágio docente ao final do semestre, aplicar um questionário de nossa autoria, com caráter mais qualitativo, no meio e no fim do semestre. Montamos um conjunto de questões abertas e, no mesmo dia da prova, pedimos que respondessem com toda a sinceridade. O feedback foi instantâneo: dois alunos, ao entregar a prova e o questionário, já elogiaram a atitude, pois mostrava que nos importávamos com o que eles, de fato, pensavam. Um deles ainda ressaltou que queria saber os resultados. Analisamos um a um, ao mesmo tempo, fazendo comentários, apontando os principais pontos, como abordaríamos com a turma e quais explicações ou mudanças faríamos. Eles pediram, dentre outras coisas, mais vídeos, mais cobrança de leitura e elogiaram o incentivo à reflexão, inclusive com o questionário. Percebi o quanto a reflexividade era dita e praticada pelo meu orientador e como isso refletia em mim e na turma, permitindo que cada pessoa desenvolva sua própria personalidade - inclusive profissional.

No dia da última prova, eu e ele conversamos sobre o semestre e sobre perspectivas futuras. Essas conversas clarearam não só "como dar aula", mas também foram tranquilizadoras sobre possibilidades vislumbradas. Preparamos, também, os questionários para eles avaliarem a disciplina novamente. Os resultados foram de reconhecimento de nosso esforço e agradecimento por incluirmos a turma nesse processo. No fim, descobri que ninguém ensina: apenas aprende.

Em suma, o semestre foi de muito diálogo entre nós e nós e a turma. Aparentemente, ter duas pessoas dando aula aproxima a turma, compartilhando atenção não somente em relação às dúvidas profissionais, mas às pessoais. A aproximação é agradável e eu realmente tenho a impressão de que isso, mais do que a formalidade, gera aprendizado. Assim como Hughes (1937) conceitua carreiras, as quais são analiticamente duais entre aspectos objetivos e subjetivos: a carreira na graduação pode separar, didaticamente, os segmentos de vida, mas, na realidade, eles são indissociáveis. Por isso, cada turma é única, como cada indivíduo é único, e as peculiaridade de espaço e tempo devem ser respeitadas e assimiladas. Por tudo isso, julgo nossa experiência conjunta de estágio bem-sucedida. E não falo só por mim: no último dia de aula, depois de uma confraternização que fizemos em sala, recebemos um livro de presente, sobre criacionismo, e uma cerveja artesanal, em agradecimento aos conselhos de tatuagem. De fato: o profissional e o pessoal indissociados.

\section{DO PROFESSOR: CONFISSÕES DE UM APRENDIZ DE MESTRE}

Nossa atuação na pós-graduação nos traz mais desafios do que muitas vezes nos damos conta. Entre eles está a contribuição na formação de futuros professores por meio do estágio docente, atividade frequentemente esquecida no decorrer de nossa trajetória, uma vez que o foco da pós-graduação tem sido predominantemente direcionado à pesquisa (BASTOS, TOURINHO, YAMAMOTO et al., 2011; JOAQUIM e BOAS, 2011). No entanto, acredito que refletir sobre a prática docente é uma responsabilidade de todo professor, logo o estágio docente é um momento fundamental para ser analisado dentro do campo da pós-graduação nacional e um espaço de conhecimento da carreira docente, um espaço a ser explorado na reflexividade (BOURDIEU, 2001) sobre nossas formas de atuação.

Quando fui confrontado com o desafio de conduzir um estágio docente, primeiramente fiquei confuso. A formação que recebemos na pós-graduação nos direciona a uma perspectiva predominantemente individual, seja como docente ou pesquisador. A sala de aula é um templo sagrado da liberdade docente e, no meu caso, que tive trajetória no teatro, "um palco" onde intercalo monólogos técnicos e científicos e interação com a plateia.

Tendo uma trajetória recente, ainda um docente guri, lancei-me ao desafio; busquei na memória como fora a formação recebida durante os estágios que realizara. Em minha trajetória, pude contar com uma orientadora que investiu em minha formação: dedicada, atenciosa e solidária, pensava como seria minha atuação em cada aula, como nossos papéis passariam de um monólogo a um dueto, como evitar choques de ideias e como indicar pontos a melhorar, um feedback construtivo e estimulante normalmente de modo informal e com descontração. Assim, começou o desafio do estágio.

Por interesse da aluna, foi feita uma primeira aproximação com a sala de aula no semestre anterior ao estágio oficial. Um acompanhamento informal no qual ela predominantemente assistia às aulas, fazendo breves intervenções. Nessa primeira interação, foi interessante observar como ela via e se apropriava dos conteúdos pela segunda vez. Havia sido professor substituto na disciplina quando ela frequentara a graduação em 2005 e não fora uma das alunas mais interessadas no conteúdo, mas já demonstrava potencial analítico-reflexivo com questões instigantes; isso nos momentos em que eu, como professor iniciante, conseguia captar sua atenção juvenil, por vezes muito distante da sala de aula. 
Passada a primeira aproximação, veio o estágio formal, registrado e acompanhado (ainda que apenas burocraticamente) pela secretaria do programa. Nesse momento, três pontos me angustiavam: 1) como integrá-la nos processos de planejamento da disciplina e avaliação (preparação, aplicação e correção de provas e trabalhos); 2) como conduzir as aulas em dueto, quando sempre aturara sozinho, assegurar o conteúdo e evitar as divergências de ideias; 3) como fazer com que a turma assumisse com naturalidade a presença de dois professores em sala de aula, quando nosso modelo de formação padronizada comporta apenas um mestre, detentor da verdade, mesmo em disciplinas compartilhadas, quando os professores em vez de buscar aprender pela interação, optam pelo revezamento.

O primeiro passo foi a elaboração do planejamento conjunto, algo particularmente difícil para mim, uma vez que sempre havia feito isso sozinho, no meu ritmo, no meu tempo. Discutimos os conteúdos, o cronograma de aulas e o processo de avaliação. Nessa fase, acredito que, por mais aberto que seja o professor, raramente o aluno se sente à vontade para dar uma sugestão que implique uma mudança maior no plano de disciplina. É a marca da separação das posições de professor e aluno sempre presente no meio universitário. Nossa conversa foi mais centrada na explicação do plano e negociação dos conteúdos em que ela atuaria com papel principal, conduzindo a aula. Busquei deixar que ela escolhesse aqueles que se sentia mais à vontade e, quando foi possível, ver como seria sua atuação em conteúdos que eu não gostava de trabalhar, pensando no que poderia aprender com sua prática.

Na primeira aula, tendo iniciado com as apresentações, troquei a terminologia de "estagiária docente" por "professora assistente" na hora de apresentá-la. Ainda que formalmente essa nomenclatura não respeite os termos legais, creio ser importante, uma vez que a palavra "estágio" carrega um elevado preconceito simbólico, ligado à precarização do trabalho e ao baixo reconhecimento. Essa primeira aula foi importante para o estabelecimento do contato com a turma, amenizando minha terceira angústia, a dupla presença docente.

No decorrer das aulas, havíamos planejado que um seria o responsável central pela aula e o outro auxiliaria. Assim, três aulas foram escolhidas e previamente estabelecidas no cronograma para ser exclusivamente da responsabilidade dela. Para as duas primeiras, ela fez uma apresentação inicial, enviou com uma semana de antecedência, sentamos e conversamos sobre os pontos que poderiam ser mais explorados, uma forma organizada de elaboração de aula. No entanto, via que essa sequência, embora necessária em um primeiro momento para dar segurança e mostrar a importância da organização, não refletia totalmente o cotidiano do professor, quando muitas vezes somos confrontados com o desafio de preparar uma aula em menos de 24 horas. Assim, quando percebi que ela estava suficientemente segura, busquei o improviso: dois dias antes de uma das aulas previstas para mim, pedi para que ela se preparasse para conduzir. Ainda me lembro do rosto em choque, dos olhos arregalados e da concordância apreensiva ao meu pedido. O resultado foi muito positivo: a aula foi conduzida com segurança, domínio de conteúdo e tranquilidade.

Um ponto fundamental foi o processo de acompanhamento semanal, ainda que tenha tido um caráter bastante informal. No final de cada aula sentávamos na cafeteria para conversar sobre a aula, discutir sobre dúvidas dos alunos, esclarecer posturas mais ou menos enfáticas na apresentação dos conteúdos, ver possibilidades de mudar as próximas aulas. Foi dessas reflexões que surgiu a intenção de elaborar um texto para refletir sobre essa experiência - uma forma de compartilhar equívocos e aprendizados.

Na condução das avaliações, encaminhei material sobre elaboração de questões e pedi que ela preparasse algumas para discutirmos. Elaboradas as questões, debatemos as respostas, dúvidas possíveis para os alunos e as integramos à prova. Na correção de provas e trabalhos, estabelecemos que primeiro ela faria a correção, encaminharia para minha revisão e, depois, discutiríamos sobre a nota final daqueles que houvesse discordância. Apesar de ser trabalhoso, não acredito que possa ser diferente: o processo de avaliação por si precisa ser pensado e refletido da elaboração à correção, numa disciplina conduzida por duas pessoas em dueto, também a avaliação é um processo construído conjuntamente.

A interação com a turma foi considerada excelente. Tínhamos um grupo muito disposto e interessado. Da discussão dos conceitos básicos de Karl Marx, Max Weber e Émile Durkheim chegamos ao debate sobre diferentes concepções do "fazer ciência" e como elas se refletiam na atualidade. Com os debates, a turma frequentemente destacava o papel político que surge no campo científico, trazendo uma perspectiva weberiana raramente refletida pelos alunos em semestres iniciais. No final do semestre, a partir do debate frequente sobre a importância de assumir posicionamento e responsabilidades nas organizações que participamos, um grupo de alunos da turma decide se candidatar para o centro acadêmico, por verem a necessidade de maior atuação discente dentro da instituição. 
Por fim, um elemento que marcou o estágio foi seu processo de avaliação, que ocorreu em duas etapas. Na primeira, realizada logo após a primeira avaliação, foi solicitado que os alunos indicassem como estava o andamento das aulas, quais técnicas utilizadas estavam sendo mais proveitosas para seu aprendizado e o que poderia ser modificado. Analisamos as respostas e debatemos as possibilidades de ajustes na disciplina, que foram proporcionados na segunda etapa. Ao final uma nova avaliação, para que os alunos pudessem pontuar o desempenho do professor, da mestranda, sua própria participação na disciplina, refletir sobre o aprendizado e indicar pontos de melhoria.

Como se pode observar, todo o processo de estágio teve grande envolvimento do professor e da mestranda, levando a um processo de aprendizado mútuo, que se refletiu em um excelente resultado no desempenho da turma.

\section{DISCUSSÕES PRELIMINARES}

Dentre as diversas reflexões que surgiram dessa experiência e que pretendemos expor por esses relatos, destacamos as três centrais. Primeiro: o processo de formação docente e os dilemas entre a preparação para o ensino e para a pesquisa, bem como as possibilidades metodológicas que percebemos. Além disso, o processo de organização do estágio e os diferentes pontos que precisam ser observados para um resultado positivo. Por fim, entendemos o estágio como um momento de aprendizado mútuo.

O estágio docente é um momento fundamental da formação docente. No entanto, percebemos que a estrutura atual desse recurso é negligenciada tanto pelos programas - como foi exposto Joaquim, Nascimento, Boas et al. (2011), Joaquim e Boas (2011) e Pena e Lima (2012) e em uma dimensão mais ampla por Cunha $(2009,2011)$ - como pelas pessoas que o experimentam; afinal, em última instância, o que existe são pessoas (SIMMEL, 1983). Dado o contexto ampliado, percebemos que o que ocorre, muitas vezes, é um dilema de vida (HUGHES, 1958), entre o status de professor e o status de pesquisador. Observando-o e vivenciando-o, entendemos que a narrativa confessional pode ajudar nesse processo, não somente como tal, mas para além dela, um "dueto confessional", no qual, durante a experiência, trocam-se confidências, alegrias e angústias, que podem facilitar os resultados positivos do estágio.

Em nossas confissões, procuramos mostrar, de início, o dilema que vivenciamos ao sermos preparados e incentivados à pesquisa - o "ser pesquisador" - e o cargo para o qual seríamos e somos designados - o "ser professor":

P: No estágio docente nos confrontamos com o desafio de "ensinar a ser professor", tarefa árdua, que, mesmo nas escolas de Educação, não há muitas certezas do "Como?". [...] Tendo uma trajetória recente, ainda um docente guri, lancei-me ao desafio...

A: Em diálogos cotidianos, a insegurança sobre o "dar aula" era quase unânime entre colegas, fazendo-nos perguntar por que raios não havia uma disciplina na pós dedicada ao tema, afinal, mesmo nos formando pesquisadores, o emprego a ser conquistado será o de professor. Novamente: Como faz?

Segundo Hughes (1958), um dilema é vivido quando a pessoa vive, ao mesmo tempo, dois status considerados díspares. Um status, para o autor, é uma posição ou rótulo social objetivo, reconhecido e estabelecido pelo grupo. Nesse sentido, percebemos dois status vivenciados na carreira acadêmica brasileira: o de professor e o de pesquisador. Como apontaram Pena e Lima (2012) e Cunha (2011), embora indissociáveis, as duas atividades requerem habilidades diferentes, muitas vezes contraditórias, que fazem ser exceção as pessoas que as desempenham com desenvoltura no mesmo momento de vida, muito provavelmente pela forma fragmentada como a atuação como professor é trabalhada nos cursos de pós-graduação.

O dilema torna-se relevante quando, saindo de um programa de pós-graduação, o qual prepara, via de regra, para formar pesquisadores, a pessoa busca por um emprego de professor. Afinal, a qual desses status eu pertenço? Para qual fui preparado? E para qual estou em busca? Na verdade, o status de pesquisador, legalmente, sequer existe no Brasil. Tais dúvidas também surgem do lado das instituições nos processos seletivos, que muitas vezes não conseguem definir claramente o status que procuram e, principalmente, no caso dos concursos públicos, regras definidas a priori podem dificultar o direcionamento do processo a um status prioritário.

Percebemos que, na ausência de um processo definido e da diferença de perfis de professores que conduzem o estágio, a pessoa que estagia pode ir do extremo de espectadora, ao outro limite, de protagonista, ou seja, pode ser tanto colocada ao 
lado dos alunos da graduação, buscando aprendizado única e exclusivamente pela observação do titular, como ser deixada sozinha com a turma, assumindo todas as responsabilidades da disciplina sem qualquer orientação. Ao mesmo tempo, o professor titular da disciplina pode ser "possessivo" ou "desapegado", encaixando-se, respectivamente, no quadro exposto.

Figura 1

\section{Representação gráfica dos papéis vividos - extremos}

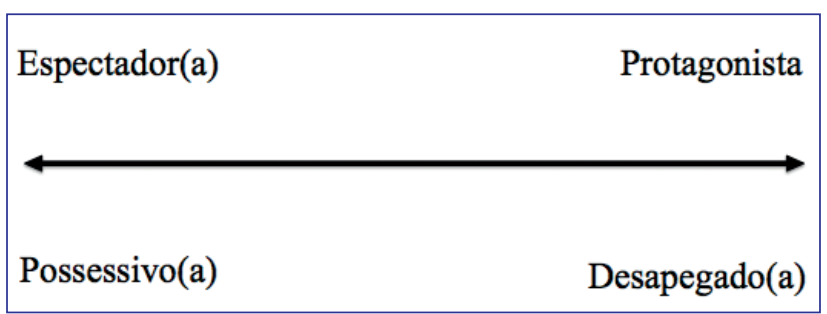

Fonte: Elaborada pelos autores.

Os termos que utilizamos em cada um dos papéis sociais extremos (espectador, possessivo, desapegado e protagonista) são didáticos, para compreensão simples por meio do nome. Nesse quadro, os quatro extremos podem estar vivenciando um conflito (HUGHES, 1937), ou seja, podem estar, objetivamente, em uma posição (estagiário e professor) e, subjetivamente, em outra (pesquisador). Isso significa que, quando vivenciado o conflito, que é viver, simultaneamente, papéis sociais (subjetivos) e status sociais (objetivos) contraditórios (HUGHES, 1937), a pessoa pode ser estagiária e viver o papel de protagonista, ao extremo. Além disso, também podem estar vivendo os dilemas já explicitados. Entendemos que, mesmo fazendo parte de uma carreira (HUGHES, 1937, 1958), tais conflitos e dilemas poderiam ser amenizados se essas pessoas deixassem de encontrar-se nos extremos desses contínuo para buscar uma posição mais central, experienciando, de fato, os benefícios que o estágio pode proporcionar. Com isso, não queremos dizer que há autonomia para essa decisão. As formas de organização e avaliação dos programas e das pessoas que fazem esses programas não só permitem, como incentivam essas contradições, formando e reconhecendo pesquisadores, mas contratando e remunerando professores.

Mesmo com estipulações formais, ao que parece, nosso dueto de trabalho poderia se encontrar ao centro desse continuum, com ambos vivenciando de uma maneira mais compartilhada a experiência. Assim sendo, dada a realidade que vivemos, na qual, estando no emprego de professor a pessoa também é pesquisador, o ponto ideal é colocar-se ao centro.

Figura 2

Representação gráfica dos papéis sociais e sua possível centralidade

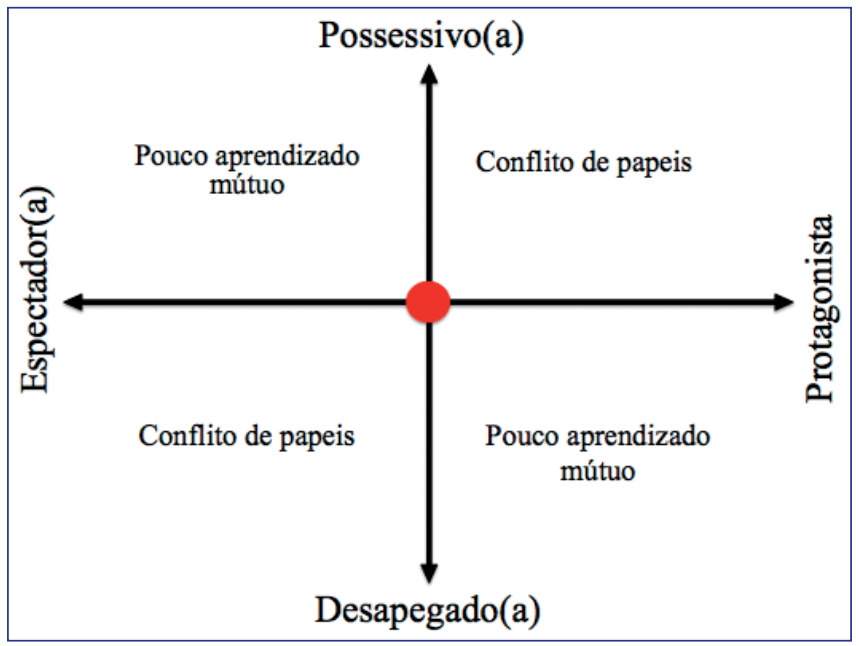

Fonte: Elaborada pelos autores. 
Com isso, não pretendemos fazer apologia ao atual contexto brasileiro de organização do trabalho dentro da academia - muito antes pelo contrário. Acreditamos que o emprego de pesquisador deveria existir legalmente, possibilitando a escolha para quem irá segui-lo - ou preferirá a docência. No entanto, apontamos para aquilo que vivenciamos, crendo que nos colocamos nessa posição central e percebendo tal atitude bem-sucedida para o tempo e espaço em que ela se colocou para nós. Como apontaria Abbott (1997), um "fato social" é um "fato social localizado", não sendo possível analisá-lo fora de seu contexto.

Das possibilidades metodológicas, ao escrever este artigo nos moldes da narrativa confessional, percebemos que, ao longo do processo de vivência, compartilhamos, resumidamente, confissões. Ao que parece, a sinceridade mútua que se estabeleceu, unida à rotina do diálogo, colaborou para que aumentássemos nosso processo de aprendizagem recíproco.

P: Um ponto importante foi o processo de acompanhamento, ainda que tenha tido um caráter bastante informal. No final de cada aula sentávamos na cafeteria para conversar sobre a aula, discutir dúvidas dos alunos, esclarecer posturas mais ou menos enfáticas na apresentação dos conteúdos, ver possibilidades de mudar as próximas aulas. Foi dessas reflexões que surgiu a intenção de elaborar um texto para refletir sobre essa experiência, uma forma de compartilhar equívocos e aprendizados.

A: No dia da última prova, eu e ele conversamos sobre o semestre e sobre perspectivas futuras. Essas conversas clarearam não só "como dar aula", mas também foram calmantes sobre possibilidades vislumbradas.

Por isso, entendemos que, além da narrativa confessional, que é uma prática posterior à experiência e compartilhada com quem lê, a vivência de um "dueto confessional", no qual as duas partes (ou mais) compartilham a responsabilidade da criação e de suas consequências. Nesse caso, a reciprocidade de aprendizado ocorreria durante o processo de trabalho conjunto, de modo a permitir feedback e subsequentes alterações, além de abrir espaço para possíveis colaborações da turma - tornando-se não só avaliados, mas avaliadores. $O$ dueto confessional, portanto, não é apenas o resultado escrito de um processo. Ele é o processo.

O segundo ponto a ser tratado, refere-se aos aspectos técnicos do estágio docente, dos quais alguns surgiram como obstáculos e, outros, como subterfúgios bem-sucedidos de prática em sala de aula. $O$ estágio docente é um processo realizado em um período estabelecido, logo, passa pelas etapas de planejamento, execução e avaliação. Tais etapas estão presentes em uma dimensão ampliada ligada à totalidade do período, mas também apresentam uma dimensão menor, com base na periodicidade das atividades, no caso em questão: as aulas semanais.

Iniciamos com o processo ampliado de estágio, ou seja, o planejamento do todo: conteúdos, sequência de aulas, bibliografia, processo de avaliação. Essa etapa ocorre algumas semanas antes do início do período letivo, na qual professor e estagiário reúnem-se para debater sobre as atividades do semestre. Quando é o primeiro estágio do aluno, o que acontece na prática é uma apresentação da disciplina por parte do professor - e menos uma discussão sobre os temas, uma vez que a insegurança e a falta de conhecimento sobre as atividades pode fazer com que o estagiário fique receoso em sugerir mudanças de maior impacto o plano da disciplina. No entanto, esse é um momento essencial do trabalho, que permite que a pessoa que estagia possa ter uma visão do todo, conhecendo a sequência de atividades de sua futura profissão.

P: O primeiro passo foi a elaboração do planejamento conjunto, algo particularmente difícil para mim, uma vez que sempre havia feito isso sozinho, no meu ritmo, no meu tempo. Discutimos os conteúdos, o cronograma de aulas e o processo de avaliação. Nessa fase, acredito que, por mais aberto que seja o professor, raramente o aluno se sente à vontade para dar uma sugestão que implique uma mudança maior no plano de disciplina. É a marca da separação das posições de professor e aluno sempre presente no meio universitário.

A: O estágio formal na disciplina "Sociologia Aplicada à Administração" começou no segundo semestre, informalmente. Iniciamos nossos encontros para discutir plano de aulas antes de termos concluído os processos burocráticos de oficialização e formalização do estágio. Esse início informal, no entanto, era necessário, principalmente para eu, como aprendiz, preparar-me com maior profundidade.

A definição do processo de avaliação merece particular atenção, uma vez que ele raramente é modificado no decorrer do semestre. Assim, é um momento importante para que se estabeleçam as tarefas de cada um no processo, com destaque para a participação do aluno na elaboração, aplicação e correção das atividades. 
No desenvolvimento de cada aula ressurge o ciclo.

1. O planejamento começa com a definição do conteúdo e dos textos a ser utilizados na aula e de quem assumirá a responsabilidade por ela: professor ou estagiário. A seguir, com a elaboração da aula, discute-se como será sua condução, dando destaque para o conteúdo (conceitos e ideias centrais) e aos procedimentos didáticos a ser adotados;

2. No decorrer da aula, buscamos fazer um dueto, onde primeira e segunda voz se alternam. Como em uma apresentação, não é o momento de fazer grandes ajustes de correções, estes devendo ocorrer no próximo ensaio o momento da apresentação central para a interação com os alunos;

3. Nosso momento de avaliação informal após cada aula contribuiu para os ajustes de trajetória, reflexão sobre o processo de aprendizagem dos alunos, identificando dúvidas e pontos que deveriam ser retomados e reflexão sobre a própria experiência docente.

A sequência de aulas, com seu ciclo de planejamento, execução, avaliação ocorreu na maior parte do semestre e serviu para o aprimoramento das práticas de professor titular e assistente.

O processo de avaliação do ciclo ampliado ocorreu em diferentes momentos, na avaliação intermediária e final realizada pelos alunos, que já foram mencionadas, na avaliação formal da "professora assistente" por parte dos alunos e do professor responsável e na avaliação final da disciplina. Nesse processo, merece destaque que em nenhum momento há avaliação do professor responsável pelo estagiário, ou pela turma, um ponto falho do processo, ou talvez a persistência da relação de assimetria de poder entre professor e aluno que marca toda a pós-graduação.

Figura 3

\section{Representação gráfica do ciclo de estágio}

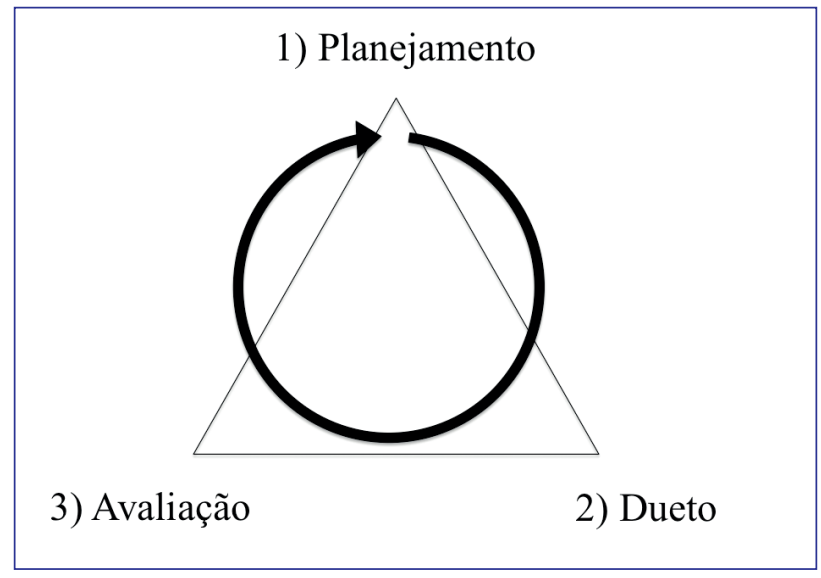

Fonte: Elaborada pelos autores.

O ciclo de realização do estágio, portanto, toma uma forma aparentemente estática, na qual, ainda que, didaticamente, apresentemos em sequência, ela se dá de modo ininterrupto. Com isso, o processo de planejamento-dueto-avaliação aconteceu paralelamente, com cada um sendo mais saliente em um ou outro momento.

Por fim, a vivência do estágio docente pode se tornar uma via de aprendizagem recíproca, na qual estagiário e professor titular descobrem o que é desempenhar essa atividade, como vivenciamos em nossa experiência. No caso que foi relatado, a empatia entre ambos e os diferentes momentos de contato no decorrer do semestre contribuíram para um processo que culminou no amadurecimento de ambos sobre a prática docente.

P: Hoje foi o último dia da disciplina de sociologia. [Nome da aluna] estava emocionada com os resultados da avaliação dos alunos. Leu as avaliações na hora, fez postagem no Facebook e a interação com os alunos continua. Acho que fiz algo certo. Certo para ela e para mim. Não foi tão difícil quanto tinha imaginado no começo. Agora é seguir firme e não entrar no piloto automático nos estágios do próximo semestre. 
A: Os resultados foram de reconhecimento de nosso esforço e agradecimento por incluirmos a turma nesse processo. No fim, descobri que ninguém ensina: apenas aprende.

Podemos observar que, nesse processo, elementos técnicos, do habitus ${ }^{2}$ da profissão (BOURDIEU, 1990, 1999) e afetivos podem ter contribuído. No que se refere aos técnicos, os encontros constantes, do processo de planejamento à conclusão da disciplina, com destaque para o processo de "reflexão-feedback" semanal auxiliaram no aprendizado de professor e aluna, uma vez que havia um espaço de troca de ideias, que no início estava predominantemente centrado na figura do professor responsável, passando orientações para a melhoria das aulas. No decorrer do semestre, no entanto, com maior experiência e segurança da professora assistente, ampliou-se para a discussão dos conteúdos da disciplina, os diferentes processos de aprendizagem dos alunos, o possível impacto da disciplina em seu futuro profissional e a consciência do papel assumido pelo professor no processo de formação.

No que se refere ao habitus profissional, merece destaque que o professor responsável é um iniciante na carreira e que essa foi sua primeira experiência de acompanhamento de um estágio docente. Sendo um novato, nem todas as estruturas estruturantes do habitus (BOURDIEU, 1990) estão incorporadas, e seus questionamentos, suas incertezas e suas inseguranças na atuação como professor contribuíram para uma maior abertura para o diálogo, tornando o espaço de interação com a professora assistente, um terreno fértil para refletir sobre a prática docente.

Já no que tange ao laço afetivo, a proximidade entre professor e aluna se iniciara na primeira experiência docente do professor responsável, quando teve a professora assistente como aluna de graduação - em 2005. Somado à memória dessa experiência, a vivência como ouvinte aparece, também, como fonte de preparação, reflexão e aproximação para o processo de aprendizagem recíproca do estágio.

P: Me divirto vendo ela em aula, parece que conheci três pessoas diferentes. a aluna meio desligada que me surpreendia com questões densas quando parecia estar numa longa viagem; a executiva que fez o processo seletivo para o mestrado e a aprendiz de professora. Imagino que ela nunca imaginou que um dia daria aula sobre Durkheim. Vai ser um aprender de novo.

A: Eu pedi a ele para assistir às aulas, sem compromisso, pois queria me familiarizar com o tema da disciplina antes de fazer o estágio formal no segundo semestre. Mal sabia eu que seria uma das minhas melhores ideias.

Além disso, entendemos como fundamental a participação como ouvinte antes do estágio formal. Com ela, foi possível compreender a disciplina como um todo, iniciando-a, no semestre seguinte, tendo os objetivos mais claros desde a partida.

Enfim, a realização da disciplina juntos foi um momento de lembrança que contribuiu para sua aproximação. Além disso, a afinidade com relação aos diferentes temas de estudo, às orientações ontológica e epistemológica e a visão sobre a necessidade de reflexão sobre a vida acadêmica facilitaram essa interação. Novamente, âmbitos objetivos e subjetivos (HUGHES, 1937), pessoais e profissionais, imbricados.

\section{CONSIDERAÇÕES PARA SEGUIR A DISCUSSÃo}

Diante de um cenário de crescimento do Ensino Superior no Brasil e de uma formação que prioriza o conhecimento em pesquisa, este estudo teve por objetivo apresentar os elementos próprios da prática de estágio docente na área de Administração, refletindo sobre ela a partir de uma narrativa confessional conjunta, uma das poucas práticas realizadas no âmbito dos programas de pós-graduação que contribui para a futura atuação em sala de aula. Com a utilização da narrativa confessional, o trabalho ainda busca fugir da estrutura tradicional de apresentação de texto, sem deixar de preocupar-se com a qualidade da discussão e articulação entre teoria e campo empírico.

${ }^{2} \mathrm{O}$ habitus pode ser entendido como "um sistema de disposições duráveis e transponíveis que, integrando todas as experiências passadas, funciona a cada momento como uma matriz de percepções, de apreciações e de ações - e torna possível a realização de tarefas infinitamente diferenciadas, graças às transferências analógicas de esquemas" (BOURDIEU, 1990, p. 86). 
A discussão estabelecida recai sobre a dicotomia presente na profissão de professor de Ensino Superior no Brasil, que é dividida entre dois status (pesquisador e docente), os quais requerem competências que nem sempre estão presentes na mesma pessoa. Além disso, nota-se uma contradição: enquanto na pós-graduação o foco direciona a formação à pesquisa, as políticas de expansão do Ensino Superior demandam um profissional com um perfil predominantemente voltado à docência.

Nessa seara de conflitos e contradições, a experiência de estágio docente nem sempre segue um processo organizado, com fases de planejamento e avaliação bem definidas, o que compromete sua execução e sua prática individual futura. Nesse sentido, o detalhamento do processo nos relatos apresentados com a perspectiva de estagiária e professor contribui para a discussão da necessidade do estágio docente ter uma organização institucional nos diferentes níveis da pós-graduação stricto sensu para que contribua efetivamente na formação do aluno. Além disso, vale destacar que, mesmo sem o aparato oficial de suporte para uma conduta apropriada de um estágio docente, de modo que haja aprendizado, é possível estabelecer uma relação de cumplicidade entre quem se compromete com a prática. Assistir a um semestre completo antes de fazer o estágio, manter um diário de campo, manter a discussão sobre o processo durante o estágio (seja entre docente e discente, seja com a turma), participar conjuntamente de todas as aulas e, principalmente, estabelecer uma relação de aprendizado mútuo, diferente da relação hierárquica, distante e corrosiva que, tantas vezes, estabelece-se entre orientado e orientador - ou professor titular.

No entanto, mais importante do que indicar procedimentos a seguir na condução do estágio docente é a reflexão sobre práticas de ensino e sobre a carreira docente. Dessa forma, este artigo não almeja alcançar conclusões, mas instigar o debate acerca: 1) das políticas de expansão do Ensino Superior e das implicações para a carreira do pesquisador; 2) a contradição dos papéis desempenhados na carreira de docente no Ensino Superior; 3 ) as responsabilidades dos professores no processo de formação de futuros docentes; e 4) o estágio docente como marco de formação para a docência.

P: Ao ser chamado a enfatizar a contribuição do artigo, recorremos novamente a narrativa confessional: "o que aprendi que merece ser registrado para a área?". A formação docente na área de Administração carece de maior atenção nos programas de pós-graduação. Para isto, é importante: a) a institucionalização de práticas organizadas para realização do estágio docente, destacando os papéis que cada um ocupa dentro das instituições; e b) como destaca Cunha (2009), trabalhar com a indissociabilidade de ensino e pesquisa na formação do professor, rompendo com a preparação fragmentada presente na maioria dos programas de pós-graduação.

A: No fim da jornada, o sentido é criado. Agora olho para trás e vislumbro uma trajetória linear, um caminho traçado, que testemunha os passos dados até aqui. A experiência do estágio, tal qual relatada, sincera, encarnada e mútua, fez surgir um real conflito: afinal, quem sou eu? Pesquisadora, aluna, mestranda, professora...? Hughes apontava que de um conflito emerge uma grande decisão; de um dilema, uma grande transformação. Tenho a certeza de que a decisão foi tomada. Dos dilemas, espero que contradigam objetividades particulares suficientes para reconhecermos o anacronismo de uma lógica que ainda colaboramos por reproduzir e que nos levem a transformações objetivas coletivas do que pode ser considerado ensino, ou melhor, como aprendizagem de qualidade. 


\section{REFERÊNCIAS}

ABBOTT, A. Of time and space: the contemporary relevance of the Chicago School. Social Forces, v. 75, n. 4, p. 1149-1182, 1997.

AZEVEDO, M. A. R.; CUNHA, M. I. Formação para a docência no âmbito da pós-graduação na visão dos seus formadores. Educação, v. 18, p. 97-104, 2014.

ALCADIPANI, R. Confissões etnográficas: fracassos no acesso à organização no Brasil. In: ENCONTRO DE ENSINO E PESQUISA EM ADMINISTRAÇÃO E CONTABILIDADE, 4., 2013, Brasília. Anais... Brasília, DF: AnPAD, 2013.

BASTOS, A. V. B. et al. Réplica 1: formar docentes: em que medida a pós-graduação cumpre esta missão? Revista de Administração Contemporânea, v. 15, n. 6, p. 1152-1160, 2011.

BEZERRA, S. A. C.; HELAL, D. H. Os desafios do recrutamento e a seleção de docentes do curso superior de administração: um estudo em Belo Horizonte. In: ENCONTRO DA ASSOCIAÇÃO DOS PROGRAMAS DE PÓS-GRADUAÇÃO EM ADMINISTRAÇÃO, 33., 2009, São Paulo. Anais... São Paulo: AnPAD, 2009. v. 1, p. 1-19.

BOURDIEU, P. Coisas ditas. São Paulo: Brasiliense, 1990.

BOURDIEU, P. Escritos de educação. Petrópolis, RJ: Vozes, 1999.

BOURDIEU, P. A miséria do mundo. Petrópolis, RJ: Vozes, 2001.

CUNHA, M. I. Trajetórias e lugares da formação do docente da educação superior: do compromisso individual à responsabilidade institucional. Revista Brasileira de Formação de Professores, v. 1 p. 110-128, 2009.

CUNHA, M. I. Indissociabilidade entre ensino e pesquisa: a qualidade da graduação em tempos de expansão. Perspectiva, v. 29, p. 443-462, 2011

CUNHA, M. I. Aprendizagem da docência em espaços institucionais: é possível fazer avançar o campo da formação de professores? Avaliação, v. 19, p. 789-802, 2014.

HUGHES, E. C. Institutional office and the person. American Journal of Sociology, v. 43, p. 404-413, 1937.

HUGHES, E. C. Men and their work. Chicago, IL: The University of Chicago Press, 1958.

JOAQUIM, N. F.; BOAS, A. A. V. Tréplica: formação docente ou científica - o que está em destaque nos programas de pós-graduação? Revista de Administração Contemporânea, v. 15, n. 6, p. 1168-1173, 2011.

JOAQUIM, N. F. et al. Estágio docência: um estudo no Programa de Pós-Graduação em Administração da Universidade Federal de
Lavras. Revista de Administração Contemporânea, v. 15, n. 6, p. 1137-1151, 2011.

JOVIANO, L. H. S. O universo da escrita de si: autobiografias, memórias, diários. In: MATA, S. R.; MOLLO, H. M.; VARELLA, F. F. (Org.). Caderno de resumos \& Anais do 2 Seminário Nacional de História da Historiografia. A dinâmica do historicismo: tradições historiográficas modernas. Ouro Preto, MG: Ed. UFOP, 2008. p. 1-9.

MILLS, C. W. On intellectual craftmanship. In: MILLS, C. W. The sociological imagination. Oxford: Oxford University Press, 1959. p. $195-226$

PENA, R. P. M.; LIMA, M. C. Entre a formação de professores e de pesquisadores nos programas de pós-graduação strito sensu em administração: contradições e alternativas.. In: ENCONTRO DAASSOCIAÇÃO DOS PROGRAMAS DE PÓS-GRADUAÇÃO EM ADMINISTRAÇÃO, 36., 2012, Rio de Janeiro. Anais... Rio de Janeiro: AnPAD, 2012.

PIMENTEL V.; MOTA, D. D. C. F.; KIMURA, M. Reflexões sobre o preparo para a docência na pós-graduação em enfermagem. Revista da Escola de Enfermagem da USP, v. 41, n. 1, p. 161-164, 2007.

RUGIU, A. S. Nostalgia do mestre artesão. Campinas, SP: Autores Associados, 1998.

SÁ, M. G.; MOURA, G. L. A crítica discente e a reflexão docente. Cadernos EBAPE.BR, v. 6, n. 4, art.8, p. 1-10, 2008.

SANTOS, K. C. G.; HELAL, D. H. O estágio docente e o desenvolvimento de competências: um estudo no Programa de Pós-Graduação em Administração da Universidade Federal da Paraíba. In: ENCONTRO DE ENSINO E PESQUISA EM ADMINISTRAÇÃO E CONTABILIDADE, 4., 2013, Brasília. Anais... Brasília, DF: AnPAD, 2013.

SIMMEL, G. Como as formas sociais se mantêm. In: MORAES FILHO, E. Georg Simmel: sociologia. São Paulo: Ática. 1983. p. 46-58.

TRAGTENBERG, M. Sobre educação, política e sindicalismo. São Paulo: Cortez, 1990.

VAN MAANEN, J. Style as theory. Organization Science, v. 6, n. 1, p. 133-143, 1995.

VAN MAANEN, J. Confessional tales. In: VAN MAANEN, J. Tales of the field: on writing ethnography. 2. ed. Chicago, IL: The Chicago University Press, 2011. p. 73-100.

VAN MAANEN, J. The present of things past: ethnography and career studies. Human Relations, v. 68, n. 1, p. 35-53, 2015.

Sidinei Rocha-de-Oliveira

Doutor em Administração pela Université Pierre Mendès-France (Grenoble 2) em cotutela com a Universidade Federal do Rio Grande do Sul (PPGA/EA/ UFRGS). Mestre em Administração pela Escola de Administração (PPGA/EA/UFRGS). Bacharel em Administração pela Escola de Administração (PPGA/EA/

UFRGS). Professor Adjunto no curso de Administração na Escola de Administração (PPGA/EA/UFRGS), Porto Alegre, RS, Brasil. E-mail:sidroliveira@ @otmail.com

Gabriela DeLuca

Mestre em Administração pela Escola de Administração (PPGA/EA/UFRGS). Mestre em Filosofia pelo Instituto de Filosofia (PPGFILO/IFCH/UFRGS).

Bacharel em Administração pela Escola de Administração (PPGA/EA/UFRGS). E-mail:deluca.gabi@gmail.com 